\title{
El VIAJE A PARÍS DE DOMINGO FAUSTINO SARMIENTO Y BENJAMÍN VICUÑA MACKENNA: MODERNIDAD Y EXPERIENCIA URBANA DE DOS FLÂNEURS HISPANOAMERICANOS
}

\author{
Domingo Faustino Sarmiento and Benjamin Vicuña Mackenna \\ travel to Paris: modernity and the urban experience of two Spanish \\ American flâneurs
}

Marcelo Sanhueza $\left(^{*}\right)$

\section{RESUMEN}

El presente artículo examina la experiencia de viaje en la ciudad de París de dos letrados criollos hispanoamericanos de mediados del siglo XIX: Domingo Faustino Sarmiento y Benjamín Vicuña Mackenna. Los relatos de viajes escritos por ambos pensadores serán analizados en torno a la importancia que el viaje tuvo en la construcción de una experiencia de modernidad en Hispanoamérica, donde París es presentada como ciudad emblema de la vida moderna y centro de la cultura occidental de la época. Para ello, problematizaremos sucintamente las conceptualizaciones de flâneur delineadas por Charles Baudelaire y Walter Benjamin en relación con el surgimiento de una subjetividad crítica de la experiencia urbana moderna en Sarmiento y Vicuña Mackenna. En este sentido, consideramos que sus relatos de viajes sobre París, funcionan como textos que, a partir de la observación in situ y desde su posición periférica en relación con

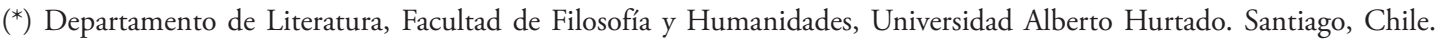
Correo electrónico: marceloivansanhueza@gmail.com 
Europa, critican el moderno modelo social y cultural que se había idealizado desde el conocimiento enciclopédico en torno a París.

\title{
Palabras clave:
}

Relato de viajes, viajero, flâneur, experiencia urbana, modernidad.

\begin{abstract}
This article examines the travel experiences in Paris of two lettered Hispanic Creoles of the mid-nineteenth century: Domingo Faustino Sarmiento and Benjamín Vicuña Mackenna. The travel writings of both thinkers will be analyzed with regard to the importance of the trips for the construction of the experience of modernity in Latin America, an experience wherein Paris is presented as a city emblematic of modern life and as the center of Western culture of that age. To this end, we will succinctly problematize the concepts of flâneur as outlined by Charles Baudelaire and Walter Benjamin in relation to the emergence of a critical subjectivity of the modern urban experience in the writings of Sarmiento and Vicuña Mackenna. In this regard, we believe that these travel writings function as texts that, through their in situ observations and from their peripheral positions in relation to Europe, criticized the modern social and cultural model that had been idealized based on encyclopedic knowledge about Paris.
\end{abstract}

Keywords:

Travel writing, traveler, flâneur, urban experience, modernity.

\section{LA IMPORTANCIA DEL VIAJE DURANTE EL SIGLO XIX EN HISPANOAMERICA: CONSTRUCCIÓN DEL CONOCIMIENTO Y EXPERIENCIA DE LA MODERNIDAD}

La emancipación política de los países hispanoamericanos durante las primeras décadas del siglo XIX representó para la élite criolla la posibilidad de una reinserción en Occidente y de una integración en los procesos modernizadores que se estaban llevando a cabo en Europa y Estados Unidos. Este proceso permitió, entre otras 
cosas, liberalizar los mercados y la circulación de saberes, puesto que anteriormente el acceso al mundo occidental había sido mediado y restringido por la administración colonial hispana (Zea, 1957). Dicha élite criolla, en general, abarcaba los múltiples ámbitos del quehacer nacional, tanto a nivel político-económico como intelectual. Eran letrados, en la terminología de Ángel Rama (1984), que dirigían los destinos de sus países pero que necesitaban en este nuevo contexto geopolítico, legitimarse en Occidente desde su propia especificidad histórica y cultural.

La práctica del viaje a Europa y a los Estados Unidos, en tal situación, se transformó, para los hispanoamericanos, en una de las formas de encontrar un lugar en el mundo y de entrar en la modernidad (Sanhueza, 2007). En este contexto, uno de los objetivos centrales fue desmarcarse del pasado colonial español que, en la óptica de los liberales criollos, fue considerado un período oscuro en la historia americana que era necesario superar (Escobar, 1980). En lo tocante a la significación del viaje a Europa, Carlos Sanhueza anota:

\footnotetext{
"La búsqueda de una identidad nacional conformó un tópico que con posteridad al proceso político de emancipación de España, se repetía una y otra vez en las preocupaciones de las elites hispanoamericanas. En tal proceso, el viaje a Europa es interpretado como una forma de evolución de lo propio, a partir de una imagen que se estructuraba al entrar en contacto con el Viejo Continente" (Sanhueza, 2006: 86).
}

El referente social y cultural, que durante más de tres siglos había sido España, es cambiado ahora, por el de naciones como Francia, Inglaterra, Alemania y Estados Unidos considerados centros culturales prestigiosos y epicentros del progreso técnico del mundo occidental (Zea, 1976).

A continuación nos centraremos en dos autores que, a mediados del siglo XIX, fueron partícipes de las transformaciones políticas, sociales e ideológicas que se gestaban en los países de la ex América española: el escritor argentino Domingo Faustino Sarmiento y el polígrafo chileno Benjamín Vicuña Mackenna. Ambos intelectuales compartieron el ideario liberal criollo, e intervinieron activamente en la vida cultural y política tanto de Chile como de Argentina. Aunque debemos mencionar que su influencia también se proyectó al resto de los países hispanoamericanos. 
Uno de los puntos en común que tiene Sarmiento y Vicuña Mackenna, es que ambos viajan a Europa en fechas muy cercanas (Sarmiento inicia su viaje en 1845, mientras que Vicuña Mackenna lo inicia en 1853) y emprenden sus travesías desde Chile, aunque por motivos distintos; motivos que explicaremos y detallaremos en el desarrollo de este trabajo. Otro punto de contacto interesante entre ambos viajeros, es el registrar su experiencia en relato de viajes, género discursivo muy utilizado en la época por los intelectuales hispanoamericanos y que según Beatriz Colombi (2006), permitió dar a conocer la situación de Occidente, considerado centro de la civilización moderna, para contrastarla con la realidad local. En este sentido, las siguientes palabras de Sarmiento pueden estimarse representativas del pensar y del sentir de su generación: "Para un americano, y particularmente para aquel que ama y busca la ciencia, no hay mayor felicidad que la de poder verificar un viajecito a la fuente de toda luz y de toda verdad en este siglo, Europa" (citado por Pierini, 1998: 178).

Hay que tener en cuenta, además, que estos relatos de viajes, en términos generales, poseen la particularidad de ser una forma de comprensión del otro, su sociedad, sus costumbres, su cultura y sus sistemas políticos, entre otros aspectos relevantes (Ette, 2001). En los casos que analizaremos, esos otros son los europeos. De esta forma, una de las consecuencias más notorias se manifiesta en las relaciones de producción del conocimiento, pues los hispanoamericanos comienzan a conformar y reforzar un saber sobre los americanos y desde los americanos, así como también acerca del mundo europeo que anteriormente se presentaba como el único capaz de generar conocimiento valioso. Como ha observado Leopoldo Zea (1976), se pretende asumir entonces una posición cultural independiente que elaborará un saber sobre los europeos desde la visión de los intelectuales criollos que tuvieron contacto directo con el Viejo Continente. Cabe precisar que ese saber sobre el otro, de igual modo, es también un saber que revela lo propio. Al respecto Ottmar Ette señala: "La multiplicación del saber sobre lo otro, sobre sus condiciones de vida y formas culturales, supone igualmente una adquisición de saber sobre el país de origen del viajero" (Ette, 2001: 52). En efecto, el análisis de los relatos de viajes de Sarmiento y Vicuña Mackenna, permite no sólo introducirnos en la imagen de Occidente que se articula en sus discursos, sino que asimismo, ayuda a comprender parte de la sociedad e ideología hispanoamericanas mientras escriben. 
Tal como ha sido estudiado por Carlos Sanhueza (2006) para el caso chileno, los viajeros fueron actores relevantes en el proceso de formación de la nación y de la identidad nacional desde la experiencia de la distancia.

Por otra parte, es importante advertir que en estos relatos de viajes también se establecen movimientos hermenéuticos de comprensión del espacio, donde se: "entretejen una red de relaciones que siempre se abren hacia un horizonte lleno de expectativas, capaz de ofrecer al público lector un precioso regalo: la posibilidad de espacializar y seguir paso a paso los movimientos hermenéuticos" (Ette, 2003: 104). Es en este aspecto donde creemos que adquieren relevancia las narraciones de Sarmiento y Vicuña Mackenna. Especialmente su experiencia de viaje por París; ciudad que se transforma en el lugar de peregrinación preferido por los intelectuales latinoamericanos de la segunda mitad del siglo XIX y, prácticamente, de todo el siglo XX. Desde esta perspectiva, París se construye como un espacio textual y cultural desde Hispanoamérica y para Hispanoamérica, a través de la confrontación de textos previos sobre la ciudad con las impresiones derivadas de la práctica cultural del viaje. La situación descrita se puede enmarcar en lo que, para Mary Louise Pratt, constituye "la reinvención de Europa" y la "autoafirmación criolla" que formaba parte del proyecto político e ideológico del liberalismo hispanoamericano. Esto "implicaba la fundación de una sociedad y una cultura americana descolonizadas e independientes, manteniendo al mismo tiempo los valores europeos y la supremacía blanca" (Pratt, 1997: 306).

Cabe destacar también que las experiencias de viaje de Sarmiento y Vicuña Mackenna pueden contextualizarse y problematizarse dentro de la experiencia de la modernidad que se comenzó a generar de modo global a través de los procesos de modernización en algunas ciudades europeas durante la época en que los letrados criollos permanecieron en París. Una experiencia de modernidad que, como ha advertido Berman, cruzó:

"Todas las fronteras de la geografía y la etnicidad, de las clases y la nacionalidad, de la religión y la ideología: en este sentido, puede decirse que la modernidad une a toda la humanidad. No obstante, esta unión es paradójica, es una unión de la desunión: nos arroja a un remolino de desintegración y renovación perpetuas, de conflicto y contradicción, de ambigüedad y angustia" (Berman, 2004: 87). 
La experiencia de viaje de Sarmiento y Vicuña Mackenna por Europa, es, a su vez, una experiencia, con sus elementos contradictorios, de la modernidad y una observación de la modernización que aún estaba en vías de expansión temprana, en tanto no constituía un proceso histórico-mundial (Anderson, 2004). Esta experiencia de la modernidad europea fue percibida y registrada por ambos viajeros en sus relatos; experiencia que asociaban fundamentalmente al mundo urbano occidental puesto que la ciudad, como ha destacado Ángel Rama (1984), se consideraba y valoraba como el espacio de civilización por excelencia. En esta dirección, la experiencia urbana por la ciudad de París se puede considerar durante el siglo XIX como la experiencia de modernidad por excelencia.

\section{DOMINGO FAUSTINO SARMIENTO, EL FLANEAR DE UN FLÂNEUR HISPANOAMERICANO}

Sarmiento fue enviado en 1845 a Europa y Estados Unidos por el gobierno chileno, específicamente por el Ministerio de Instrucción Pública, para realizar investigaciones sobre los sistemas públicos de instrucción primaria de los principales países occidentales de la época. Además, tuvo la misión política de evaluar el potencial inmigratorio para la colonización del sur de Chile; aunque más allá de estas circunstancias políticas, su periplo, como bien indica Margarita Pierini, “constituye una empresa de búsqueda y descubrimiento" (Pierini, 1998: 178). Durante su viaje (1845-1848), visitó Francia, España, Italia, Suiza y Alemania, también el norte de África y Estados Unidos. A partir de su experiencia viajera escribió un libro que recopila una serie de cartas enviadas a diversos actores del acontecer político de Chile y Argentina. En este contexto se enmarca la carta que escribió en París el 4 de septiembre de 1846 dirigida a Antonino Aberastain, político argentino y amigo de Sarmiento, a quien relata su experiencia en la ciudad luz. Al inicio de la misiva hace la siguiente petición: "Lea lo que le escribo con atención de este París encantado" (Sarmiento, 1997: 99). La petición corrobora la vital importancia que posee la ciudad de París en la perspectiva del escritor argentino y que ya había manifestado en una carta anterior enviada a su amigo Carlos Tejedor, en mayo de 1846, desde la ciudad de Ruan, cuando escribe: "Avise usted a los míos, mi buen amigo, que he tocado tierra en Europa, que he abrazado, mas bien dijera, esta Francia de nuestros ensueños" (Sarmiento, 1997: 75). El "ensueño" se relaciona con la posibilidad de conocer la ciudad considerada por 
su generación como el corazón de Europa y "es desde allí donde la luz y la verdad se encuentran elevadas a su máxima potencia, al alcance del viajero que sepa descubrirlas y que se anime a hacerlas suyas" (Pierini, 1998: 178-179).

Sarmiento arriba al París que el pensador alemán Walter Benjamin consideró "capital del siglo XIX". Ciudad donde surgen figuras de la talla de Baudelaire y Balzac, la bohemia y las barricadas, las Exposiciones Universales y los panoramas y, por cierto, el flâneur; personaje que vagabundea sin mayores objetivos por sus calles y bulevares. Para Benjamin, es la figura representativa del París de mediados del siglo XIX que reconoce en todos aquellos sujetos marginales (vagabundos, prostitutas, ebrios) definidos por la experiencia del callejeo por los bulevares, pasajes y panoramas. Como se observa, el flâneur es una figura típica de la época en que Sarmiento y Vicuña Mackenna viajan y escriben sus relatos, y dice relación con el impacto que la modernización parisina provocó en sus habitantes y visitantes.

El viaje de Sarmiento se da en ese París de la bohemia y del flâneur. En esta situación, nos surge la siguiente interrogante: ¿en qué medida la experiencia de Domingo Faustino Sarmiento en París, puede ser interpretada como la de un flâneur?

Sarmiento recorre y se desplaza por el París de Baudelaire. Ese París que se encuentra en el período de transición entre las reminiscencias revolucionarias y el capitalismo fetichista de la mercancía. Sin embargo, no es nuestra intención calificar a Sarmiento directamente como un flâneur del modo que lo propone Benjamin, ya que su experiencia y relación con la metrópoli francesa tiene ciertas singularidades que son necesarias de advertir. Cabe señalar al respecto, que Sarmiento tiene su propia concepción del flâneur que introduce, hasta donde sabemos, en la cultura y letras hispanoamericanas:

"El español no tiene una palabra para indicar aquel farniente de los italianos, el flâner de los franceses, porque son uno i otro su estado normal. En Paris esta existencia, esta beatitud del alma se llama flâner, no es como flairer, ocupación del ujier que persigue al deudor. El flâneur persigue también una cosa, que él mismo no sabe lo que es; busca, mira, examina, pasa adelante, va dulcemente, hace rodeos, marcha i llega al fin... a veces a orillas del Sena, al boulevard otras, el Palais Royal con más frecuencia. Flanear es un arte que solo los parisienses poseen en todos sus detalles; i sin embargo, el estranjero principia el rudo aprendizaje de la encantada vida de Paris por ensayar sus dedos torpes en este instrumento de que solo aquellos insignes artistas arrancan inagotables armonías" (Sarmiento, 1997: 99). 
Es interesante examinar en este pasaje cómo Sarmiento se apropia del término flâneur para dar a conocer a sus lectores hispanoamericanos, una forma particular que los franceses tienen para relacionarse con su ciudad capital. A diferencia de la teorización benjaminiana, lo que hace Sarmiento es entregarnos una visión del flâneur desde el propio París decimonónico. En este escenario, piensa que el flâneur corresponde una experiencia que sólo se produce en esta ciudad, que considera "un pandemónium, un camaleón, un prisma” (Sarmiento, 1997: 102), en los múltiples planos: intelectual, literario, artístico y político. Es una ciudad donde, para él, todo existe y se manifiesta principalmente en el incesante y febril tránsito urbano.

Sarmiento se comporta como un mediador cultural: traduce en un discurso legible, para los hispanoamericanos, su experiencia viajera. De esta forma, construye una imagen del mundo moderno comprensible para sujetos que están distantes de las transformaciones culturales, políticas y económicas que se desarrollan en Europa (Pratt, 1997: 334). En dicha perspectiva, según Mary Louise Pratt, "Sarmiento no llega a París, su Meca cultural, como conquistador, sino como infiltrado. No adopta la posición del veedor, que contempla panorámicamente un París radicalmente diferente de él mismo. Sarmiento se introduce en París desempeńando el papel del flâneur quien, sostiene, es el observador privilegiado de la ciudad" (Pratt, 1997: 332). Como ya hemos indicado, Sarmiento no es exactamente un flâneur benjaminiano, debido a que no está ni fuera ni dentro de la sociedad capitalista, es decir, no es un sujeto marginal de la ciudad, sino que un extranjero. En este escenario, el viajero es entonces un sujeto periférico con respecto a la norma eurocéntrica, condición que lo hace adoptar una actitud distante y crítica en medio de la multitud, aflorando un sentimiento de soledad frente a la ciudad moderna:

"Je flane, yo ando como un espíritu, como un elemento, como un cuerpo sin alma en esta soledad de París. Ando lelo; paréceme que no camino, que no voi sino que me dejo ir, que floto sobre el asfalto de las aceras de los bulevares. Solo aquí puede un hombre injenuo pararse i abrir un palmo de boca contemplando la Casa Dorada, los Baños Chinescos, o el Café Cardinal. Solo aquí puedo a mis anchas estaciarme ante las litografías, grabados, libros i monedas espuestas a la calle en un almacen, recorrerlas una a una, conocerlas desde léjos, irme, volver al otro día para saludar a la otra estampita que acaba de amanecer" (Sarmiento, 1997: 100). 
Sarmiento es un paseante que se entrevista con hombres clave del mundo político y cultural de París, tales como Guizot, Thiers. Incluso se reúne con el autoexiliado José de San Martín. Todas estas reuniones son registradas con meticulosidad por el argentino en su "Carta”, lo que manifiesta el afán de creación de autoridad que busca establecer en su discurso. Al mismo tiempo, expresa su preocupación por el sistema político francés, sistema que, según él, está también signado por el movimiento constante de la metrópoli moderna: "los hombres andan afanados registrando la historia de los tiempos pasados, compulsando las fechas, corrigiendo los errores, reproduciendo libros olvidados, tomando un camino i dejándolo al día siguiente para echarse en otro. Nadie es hoy lo que ayer era” (Sarmiento, 1997: 103).

Durante su estadía en la capital francesa, Sarmiento asiste al Parlamento, a museos y a todos aquellos sitios de interés para los visitantes. Aunque será el Parlamento la institución por la que muestra mayor interés, pues representa el espacio político y republicano por excelencia. En su Argentina natal, en cambio, este espacio democrático ha sido destruido por el gobierno de Juan Manuel de Rosas. En este contexto, Sarmiento describe con meticulosidad una sesión del Parlamento donde se expresan, de acuerdo a la perspectiva ideológica del viajero, las posiciones políticas contrarias: "están la alegoría de la fuerza, contrapuesta a la de la prudencia; el órden público a la libertad; la justicia a la elocuencia" (Sarmiento, 1997: 110).

Ahora bien, el escritor argentino, a partir de su experiencia urbana, reflexiona asimismo acerca de la situación privilegiada que tienen los extranjeros en algunos lugares de las ciudad: "Solo en Paris tambien, el estranjero es el dueño, el tirano de la ciudad. Museos, galerías, palacios, monumentos, todo está abierto para él, menos para el parisiense, a toda hora i en todos los días. Mostrar su pasaporte a la puerta, es mostrar un firman ante la cual se quita el sombrero el conserje" (Sarmiento, 1997: 101). Desde este punto de vista, su experiencia se puede interpretar bajo la figura del flâneur, aunque un flâneur particular. Tal como lo indica Víctor Barrera Enderle, Sarmiento se puede considerar un flâneur, "con la salvedad de que su conducta persigue un fin opuesto al de este sujeto moderno metropolitano: él no anda en pos de esparcimiento caótico o rebelde, sino del conocimiento, basando su conducta en el aprendizaje de la teoría a través de la práctica y en la selección de todo aquello que pueda ser útil a los pueblos hispanoamericanos" (Barrera Enderle, 2005: 18). Además, es crítico e irónico en relación con el uso indiscriminado que 
le dan los parisinos a la experiencia del flanear y del flâneur:

"Es cosa tan santa i respetable en Paris el flaner, es una función tan privilejiada que nadie osa interrumpir a otro. El flaneur tiene derecho a meter sus narices por todas partes. El propietario lo conoce en su mirar medio estúpido, en su sonrisa en la que se burla de él, i disculpa su propia temeridad al mismo tiempo. Si Ud. se para delante de una grieta de la muralla i la mira con atencion, no falta un aficionado que se detiene a ver que está Ud. mirando; sobreviene un tercero, i si hai ocho reunidos, todos los paseantes se detienen, hai obstruccion en la calle, atropamiento. ¿Este es, en efecto, el pueblo que ha hecho las revoluciones de 1789 i 1830? Imposible! I sin embargo, ello es real; hago todas las tardes sucesivamente dos, tres grupos para asegurarme de que esto es constante, invariable característico, maquinal en el parisiense” (Sarmiento, 1997: 100).

Esta reacción que tiene Sarmiento en contra de la superficialidad del flâneur, expresa las contradicciones que visualiza en una sociedad con una tradición intelectual donde se originan las revoluciones de corte republicano. Mary Louise Pratt (1997) observa en esta pregunta final del trasandino, una actitud demasiado republicana y pragmática. Actitud que se relaciona con el lugar de enunciación que adopta el viajero, en tanto el origen no-europeo no le permitiría comprender a cabalidad la cultura parisina. Lo que hace Sarmiento en su crítica a la forma superficial e incluso estulta que tienen los franceses en su callejear por la ciudad, es desmitificar en cierta medida el prestigio del estereotipo cultural que se había construido discursivamente en Hispanoamérica en torno a los franceses. Para el autor de Facundo, son hombres simples que los hispanoamericanos fácilmente pueden superar en inteligencia y costumbres. Esto es posible siempre y cuando se los imite, algo que parece contradictorio, pero que durante el siglo XIX era perfectamente compatible con el proyecto nacional. En tal sentido, es generalizado en esta época encontrar intelectuales que rescatan y admiran a la cultura francesa, inglesa, alemana y estadounidense, en lo tocante a la alta cultura, la técnica, la política y el comercio; sin embargo, mantienen una posición nacionalista (Zea, 1976).

El horizonte de expectativas de Sarmiento sobre París, construido a partir de discursos y lecturas anteriores, donde los franceses aparecen como la cuna y centro de la cultura moderna, se tensiona y en muchas ocasiones se rompe ante la experiencia in situ. El viajero se posiciona en París como un hombre que está buscando un modelo de modernidad y una imagen de modernidad que sea útil para los hispanoamericanos, seleccionando los aspectos que considera relevantes 
para su sociedad. De todas formas, en Europa se siente parte de una civilización común: "Siéntome que no soy huésped ni extranjero [en Europa] sino el miembro de la familia que se acerca al hogar de sus antepasados" (Sarmiento, 1997: 76). La construcción narrativa de su experiencia viajera cumple entonces la función de acercar a "la familia", que debido a circunstancias geográficas y políticas ha quedado distanciada.

Así entonces, podemos postular que Sarmiento es un flâneur hispanoamericano que tiene una experiencia diferente con la ciudad de París, pues en relación con la norma occidental "viene de un país marginal y periférico" (Zilly, 2010: 150). Por un lado, se deja llevar por el callejeo simple y sin sentido; aunque por otro, en su condición de sujeto foráneo, se sitúa críticamente y busca, como ya hemos destacado, apropiarse de todos los elementos que sean de utilidad para las naciones de Hispanoamérica. Desde su punto de vista, la ciudad de París, y por extensión Francia y los franceses, es el modelo de civilización a imitar por los países de las "Tierras Bajas", como denomina el argentino al mundo hispanoamericano. Sarmiento, más allá de algunas críticas a la sociedad francesa, considera en definitiva que: "El francés de hoy es el guerrero mas audaz, el poeta mas ardiente, el sabio mas profundo, el elegante mas frívolo, el ciudadano mas celoso, el joven mas dado a los placeres, el artista mas delicado, i el hombre mas blando en su trato con los otros" (Sarmiento, 1997: 123).

De esta forma, en la perspectiva ideológica de Sarmiento París se presenta como el centro y emblema de la cultura occidental. Es la ciudad donde él salta hacia el futuro deseable para los países hispanoamericanos, pero con los ajustes y mejoras que requerían, según él, nuestras circunstancias. En tal situación, gracias a su experiencia en París, piensa que un modelo de modernidad y de progreso es precisamente esta ciudad. Sarmiento procura, entonces, explorar la vida urbana moderna en su conjunto, porque en su interior puede examinar con mayor detención los planos políticos, sociales y culturales que son ejes centrales de su relato de viajes.

Como hemos revisado hasta aquí, en París el escritor argentino busca un modelo de sociedad que, sin embargo, no comprende ni comparte por completo debido a que su cultura está inscrita, aunque se considere un miembro de la "familia", en 
las tradiciones y costumbres de un mundo altamente ligado a la herencia colonial hispana como lo advirtieron Bello y Bilbao en sus reflexiones:

\footnotetext{
"Paris es, por otra parte, poco ceremonioso en materia de costumbres privadas, i seria largo recorrer la escala que media entre la prostituta i la mujer casada, entre cuyos estremos se encuentran gradaciones del matrimonio, admitidas por la sociedad, justificadas por las diversas condiciones, i por tanto respetadas. De aquí nace a mi juicio la cultura de las mujeres de Francia, la gracia infinita de la parisiense, i el vestir igual, en su caprichosa variedad, de todas las clases de la sociedad" (Sarmiento, 1997: 103).
}

En este fragmento identificamos un rasgo conservador del viajero en torno a las relaciones de pareja y en su calidad de extranjero se presenta distante de las costumbres parisinas que probablemente no estaban lo suficientemente descritas en los libros que había leído previamente sobre la metrópoli. En esta perspectiva, lo propio funciona como norma desde la cual contrasta y valora a la sociedad de París. Si bien, en general, los modelo de progreso y cultura son para Sarmiento Europa y Estados Unidos, las costumbres de dichas sociedades son sopesadas y apropiadas reflexivamente en el marco del proyecto de formación nacional hispanoamericano, desestimando aquellos aspectos que no están acordes con sus valores sociales y culturales.

En resumen, la experiencia de viaje por París como un flâneur le permite a Sarmiento construir textualmente una perspectiva crítica sobre la sociedad parisina y la vida moderna, presentando la superficialidad y los goces como una característica inherente de su sistema social.

\section{BENJAMÍN VICUÑA MACKENNA EN PARÍS: EXPERIENCIAMODERNA Y RETÓRICA DEL PASEO}

El caso de Benjamín Vicuña Mackenna presenta mayores complicaciones a la hora de considerar su experiencia parisina a la luz de la figura del flâneur. Sin embargo, antes de entrar en esta problemática es necesario contextualizar sucintamente el viaje del polígrafo chileno. Vicuna Mackenna emprende su viaje por razones políticas, quien en su calidad de miembro de la Sociedad de la Igualdad apoyó el levantamiento militar del Coronel Urriola, el 20 de abril de 1851, en contra del presidente conservador Manuel Montt. Tras el fracaso de dicho levantamiento 
fue condenado a muerte junto con otros simpatizantes de la revuelta (Donoso, 1925). Por esta razón, partió al exilio entre noviembre de 1852 y octubre de 1855. Durante su ostracismo viajó por México, Estados Unidos, Canadá, Inglaterra, Francia, Italia, Alemania, los Países Bajos, las costas de Brasil y las provincias del Río de la Plata. En estos lugares escribió un diario de viajes que a su regreso a Chile publicó en 1856 por entregas en el periódico El Ferrocarril.

En lo capítulos correspondientes a su periplo europeo Vicuña Mackenna describe las contradicciones del mundo occidental y crítica los sistemas políticos, sociales y económicos de sus países más representativos: Inglaterra, Francia, Alemania, entre otros. En todo caso, es siempre cauteloso en relación con la valoración de todos aquellos aspectos que podrían resultar beneficiosos para Chile y para los países de la ex América espańola, actitud similar a la adoptada por Sarmiento en su relato.

Ahora bien, una vez dentro de Europa, específicamente en Francia, el objetivo central de Vicuña Mackenna es instalarse en París y desde ahí evaluar a la sociedad francesa en general. Dicha ciudad era considerada, como ya se ha señalado, el centro de la civilización y arquetipo de la vida moderna (Berman, 2006: 147), tanto para las élites europeas como para las élites hispanoamericanas durante prácticamente todo el siglo XIX. La impresión del viajero al hacer su arribo a París explicita la relevancia que tiene la ciudad en su imaginación, puesto que también la exalta como la "capital del mundo" (Vicuña Mackenna, 1936, Vol I: 303):

"Estaba ya en París, realizado el sueño de la mitad de la vida y la imaginación adormecida otra vez en sueños de admiración y de portento! Estaba en la capital del mundo, el corazón de la humanidad en que todo parece latir con las pulsiones gigantescas que el espíritu de todos los pueblos envía a este centro de vida y de inteligencia. Miniatura del Universo, aquí existe todo lo creado [...] Voltaire y Rousseau, Mirabeau y Napoleón, Chateaubriand y Lamartine; todo lo ha engendrado París en los 70 años que van corridos desde el 89! Cuna y sepulcro, cadenas y libertad, hoy dictando la ley, mañana bajo la bota de un soldado. París, empero, se encontrará siempre sobre la faz de la tierra como el faro que ilumine o extravíe al género humano en su camino!” (Vicuña Mackenna, 1936, Vol I: 281-282).

En estas líneas advertimos que coincide, en cierta medida, con la retórica de Sarmiento en tanto París se presenta como el lugar de "sueños de admiración y de portento". Es importante destacar que esta retórica que sitúa a París como el espacio cultural y textual del ensueño y del deseo se proyecta, como hemos 
advertido, hasta los escritores modernistas que otorgan un lugar privilegiado a esta ciudad.

Vicuña Mackenna prosigue con el encomio de la ciudad que le permite subrayar aún más el prestigio y trascendencia de la capital francesa en el marco de la cultura occidental y del lugar fundamental que ocupa entre los letrados hispanoamericanos:

"Tres ciudades, se ha dicho, han reasumido en sí la época del mundo en que existieron: Atenas, Roma y París. Pero París ha reasumido ambas; hijo de Minerva, París ilumina la tierra; hijo de Marte, París ha subyugado el Universo. París es el daguerrotipo de la humanidad, el epítome de la historia, la base y la cúspide de la civilización moderna. París es único; esclavo hoy día de un aventurero, París es todavía el amo de la Europa y del orbe” (Vicuña Mackenna, 1936, Vol I: 282).

En los pasajes citados se han puesto en juego los referentes enciclopédicos y discursivos que configuran la visión previa sobre la ciudad, una biblioteca mental que porta el viajero y desde la cual enfrenta su experiencia empírica. Así, se devela un rasgo importante de su perspectiva ideológica que, al igual que Sarmiento, encuentra sus fuentes en el pensamiento político ilustrado. No obstante lo anterior, estos referentes en torno a ese París de ensueño se desvanecen rápidamente tras internarse por las calles de la ciudad:

"Pero cuando apenas dejaba la Estación del camino de hierro para dirigirme al otro lado del Sena, y vi calles y casas y gente y bodegones, y veredas enlodadas y ventanas cubiertas de polvo y tela arañas; cuando pasaba por la plaza del Carrousel y veía el Louvre convertido en escombros y las Tullerías como un inmenso galpón de piedra, por pueril que fuera mi desencanto, tuve más de una vez la tentación de apearme del fiacre que me llevaba y preguntar al cochero si aquél era verdaderamente París! el París de mis ilusiones!" (Vicuña Mackenna, 1936, Vol I: 282-283).

En este momento se tensionan y cuestionan las preconcepciones del viajero sobre la ciudad luz, que sin duda era la ciudad de la cual tenía mayores informaciones en tanto "figuraba como la cima de la Revolución y atraía a todos los espíritus liberales del mundo" (Ferrándiz Alborz, 1953: 201). El recorrido visual que textualiza el viajero va delineando esa mirada crítica que lo caracteriza, al contraponer los lugares indirectamente conocidos con los presenciados personalmente termina expresando un "desencanto" similar al que le produce la ciudad a Sarmiento. 
En París Vicuña Mackenna realiza, además, visitas a museos, bibliotecas, universidades, teatros, palacios, cafés, cementerios, bulevares y todos los rincones que la ciudad podía ofrecer a un extranjero con interés por la cultura. Le preocupa internarse en la ciudad, escudriñar y observar con agudeza los comportamientos de sus habitantes. Las artes, el comercio, la moda, el materialismo y el cosmopolitismo son los temas en torno a los cuales constantemente reflexiona. Vicuña Mackenna en este lugar recorre, observa e interpreta sus espacios públicos, configurando en su relato anticipadamente ciertos rasgos de esa subjetividad burguesa latinoamericana desarrollada por cronistas urbanos finiseculares como Martí, Gutiérrez Nájera, Gómez Carrillo, Darío entre otros (Ramos, 2003: 150). El análisis de la sociedad parisina que presenta, pasa por una retórica del paseo que ordena y clasifica la ciudad, "estableciendo articulaciones, junturas, puentes, entre espacios (y acontecimientos) desarticulados" (Ramos, 2003: 166). Como el mismo viajero confiesa: "yo visitaba las curiosidades de París como de ocasión, al pasar” (Vicuña Mackenna, 1936, Vol I: 295).

Debemos indicar que Vicuña Mackenna, a diferencia de Sarmiento, no escribe acerca del término flâneur, es más ni siquiera lo utiliza, aunque en muchas oportunidades la mirada que se configura en su discurso se puede interpretar como la experiencia de un flâneur similar a la problematizada por Benjamin. Esto es posible identificar en diversos momentos del relato, donde el viajero nacional nos describe la especial relación que establece con la ciudad de París cuando se dedica a callejear por sus rincones:

\footnotetext{
"Recordaré aquí también uno de los primeros días de mi llegada, en que me propuse seguir sin guía ni preguntas, el torrente humano que en todas direcciones se cruzaba; sería un ensayo para mí de lo que significa una jornada en París, en contraste con la marcha metódica que había llevado otras veces. (...) Penetré desde luego por los Boulevards de la calle Saint Denis, maremagnum de confusión y ruidos, donde se encuentra algo que revela de un golpe esa originalidad parisiense, única en el mundo. La variedad, el movimiento, el tumulto, la inquietud voraz de cada uno; una tienda de Paturot, otra de cordones, cintas y medias; una carnicería, una casa de huéspedes, un restaurant, una casa de baños, una pastelería, todo junto: todo en hilera, todo revuelto, todo al revés y al derecho. (...) Todo era un laberinto, un maremagnum, un mundo revuelto, un París..." (Vicuña Mackenna, 1936, Vol I: 334-335).
}

París es entonces una urbe a la que no consigue encontrarle un orden social aceptable, porque pese a sus notables conocimientos y lecturas previas sobre 
esta ciudad, en su paseo "sin guías ni preguntas" se pone en evidencia que él no pertenece a ese sistema social; de ahí se derivaría su distancia y asombro. Asimismo, esta escena expresa en el "torrente humano que en todas direcciones se cruzaba", un testimonio de la compleja percepción e interpretación del mundo moderno por parte del viajero. Para hacer inteligible su experiencia urbana a los posibles lectores chilenos y sudamericanos, Vicuña Mackenna elabora una retórica del paseo mediante la utilización de términos y sintagmas como; "movimiento", "maremagnum de confusión y ruido", "variedad", "tumulto", "inquietud voraz", "un mundo revuelto". Retórica que acentúa y ahonda su visión crítica sobre el movimiento y el caos que observa en la ciudad moderna, especialmente en los bulevares.

A partir de estas consideraciones, la imagen que Vicuña Mackenna textualiza sobre la ciudad no está tan alejada de las imágenes que podemos reconocer en el escritor insigne del París decimonónico, Baudelaire. Poeta que, como hemos señalado, teorizó sobre el vagabundear por esta ciudad como la experiencia del flâneur (de la que también escribe Sarmiento). Como hemos revisado hasta ahora, Vicuńa Mackenna fue un profundo observador de la sociedad parisina, logrando captar algunos de los conflictos político-sociales que la caracterizaron durante la segunda mitad del siglo XIX. En este sentido, la imagen que nos ofrece de los bulevares tiene un especial atractivo porque consigue interpretar y comprender, en cierta medida, la transformación social que éstos produjeron en la capital francesa, donde la muchedumbre transitaba sin una organización aparente entre un conjunto de sitios dedicados al comercio (restaurantes, carnicerías, casas de baños, pastelerías, entre otros), que, para él, tampoco respondían a una concepción adecuada del orden citadino. La imagen de la ciudad y del mar humano que se da en su interior, es a nuestro juicio, un testimonio de lo complejo que resulta para Vicuńa Mackenna narrativizar y explicar su experiencia en una sociedad que se presenta extrańa a los ojos de un sudamericano de la época.

Ahora bien, Vicuña Mackenna busca al interior de los bulevares aproximarse compresivamente al espacio citadino desde un ángulo más íntimo, pues pretende internarse en París como si fuere un ciudadano más, eludiendo: "la marcha metódica que había llevado antes". Aunque no por ello se siente cómodo en ese transitar caótico de sus ciudadanos. Pese a ello, su deambular por los bulevares 
puede ser considerado como una experiencia cautivadora para sus lectores que no han visitado París, y que quizá conservan ideas e imágenes anacrónicas e inadecuadas sobre la ciudad. En cierto sentido, la experiencia textualizada por Vicuńa Mackenna en medio de las calles parisinas, escenifica la imagen del hombre moderno, que "es un peatón lanzado a la vorágine del tráfico de una ciudad moderna, un hombre solo que lucha con un conglomerado de masa y energía que es pesado, rápido y letal" (Berman, 2006: 159). Tras este deambular sin una dirección fija se encuentra, como vimos, con que: "Todo era un laberinto, un maremagnum, un mundo revuelto, un París", imágenes laberínticas que intentan plasmar en la escritura sus percepciones surgidas a partir del callejear "sin guías" por la ciudad. Es posible interpretar, además, que estas imágenes que hacen una constante referencia al movimiento y al desorden, sirven para traducir y registrar en el relato el proceso de modernización de París. Modernización que, como expusimos al comienzo, en esa época todavía no alcanza por completo a las ciudades hispanoamericanas, donde la estabilidad y el orden son parte de las concepciones urbanísticas predominantes para la clase dominante criolla.

En la esfera política, Vicuña Mackenna se dedica a examinar el accionar del gobierno monárquico de Napoleón III, por el que expresa una profunda aversión, ya que lo considera un gobierno que actúa de forma inicua contra sus ciudadanos:

"En los tribunales correccionales se juzgan casos muy originales, los más de moda eran los insultos de palabras dichas contra el Emperador, delitos de los más graves en esta época de adulación; esto era repugnante. Otros casos eran ridículos; cierto día, a pesar de sus lágrimas, una pobre muchacha fue condenada a un mes por haber hurtado un melón!" (Vicuña Mackenna, 1936, Vol I: 294).

Esta descripción del proceder de la justicia francesa, sumisa al Emperador, le recuerda a la justicia chilena que lo había desterrado del país en complicidad con el gobierno de turno: "Yo recordaba entonces haber visto, en el Juzgado sumariante de Santiago, condenar a tres y más meses de presidio a reos que no tenían más acusación que un parte del comandante de los serenos, ni más abogado que el ordenanza que los introducía a presencia del juez y del escribano..." (Vicuńa Mackenna, 1936, Vol I: 295). Con este ejercicio de memoria realiza una doble crítica desde la distancia: una crítica a la Francia de Napoleón III y también una crítica artera a la administración del presidente Bulnes, quedando en evidencia las 
motivaciones políticas subyacentes en su discurso.

En opinión de Vicuña Mackenna, la política de Napoleón III ha sido nefasta para las libertades de los franceses y, en consecuencia, su figura conjuga los retrocesos de la política del Viejo Continente que había reinstalado en el poder a las rancias monarquías:

"Las fiestas de la libertad han quedado hoy reducidas en Europa al último acto de la vida, delante de la fosa de algunos de sus defensores; pero el despotismo, en la cúspide de su omnipotencia, se empavona con todas las galas de la ostentación. La fiesta de la [sic] San Napoleón, el 15 de agosto, es el gran día del Imperio, y es celebrada más bien como las bacanales del Bajo Imperio que como los Juegos Olímpicos de la Grecia" (Vicuña Mackenna, 1936, Vol I: 339).

Esta imagen de una Francia y una Europa oprimida por el despotismo de sus monarcas que no han respetado a quienes combatieron en pro de la libertad, causa un profundo desdén en el viajero, quien compara las fiestas del emperador francés con una bacanal romana. Señala también sobre la administración del emperador: "Su tiranía era absoluta y terrible como la ignominia y el avasallamiento de la Francia en la época en que yo llegaba a París" (Vicuña Mackenna, 1936, Vol I: 344).

Tras presenciar las celebraciones de "San Napoleón", Vicuña Mackenna reflexiona sobre cómo una sociedad con una tradición revolucionaria fundamental para la historia mundial se ha convertido en algo abyecto que sólo pide "Pan y Fiesta":

“QQué sitio de París no trae a la memoria alguna de las tradiciones sociales y políticas, ya terribles, ya sublimes que desde 89 han regenerado el mundo? Me encaminaba hacia el Puente de Jena, alejándome de aquella fiesta que tenía tanto de banal y miserable, y que habría hecho pensar en el pueblo que pedía sólo Pan y Fiesta, cuando gritos confusos y prolongados llegan hasta mí [...] Se percibían los gritos de l' Empereur! l' Empererur hasta que al fin la ola humana se detuvo, y yo, sin saber cómo, me encontré estrechado contra la rueda de un carruaje; eran el Emperador y la Emperatriz de son peuple" (Vicuña Mackenna, 1936, Vol I: 343).

En esta escena, Vicuña Mackenna se autorrepresenta como un actor de la historia, encontrándose cara a cara con el monarca galo, representante del poder opresivo 
del pueblo francés. A dicha escena añade con ironía antimonárquica: "Yo podía tocar la mano del Emperador con la mía, pero confieso que poco me cuidaba de aspirar a tal honor, tratando de protegerme contra aquella apretura" (Vicuña Mackenna, 1936, Vol I: 343). Para el viajero, este emperador es sólo un hombre que ha destruido los movimientos revolucionarios y que domina sin contrapeso las diferentes esferas de la vida pública. Es el que le arrebató "a la administración pública todo lo que tuviera de inteligente, de digno, de patriota y que pudiera oponérsele como una resistencia" (Vicuña Mackenna, 1936, Vol I: 344). Logró, según Vicuña Mackenna, que los: "más ilustres profesores abandonaran así sus cátedras" (Vicuña Mackenna, 1936, Vol I: 343) y los colegios fueron entregados a la obsecuente dirección "del espíritu jesuítico que Luis Napoleón ha resucitado con la Orden en Francia; espíritu jesuítico que no significa ya la ambición universal de la gran Orden extinta, sino el miserable materialismo de los negocios, del dinero, y de una influencia dirigida puramente a la posesión del elemento material de la existencia" (Vicuña Mackenna, 1936, Vol I: 344-345). Según él, el emperador incluso había conseguido transformar a la prensa parisina en un medio servil a su gobierno. Para ratificar lo anterior, el viajero nos entrega los siguientes datos: "De los 10 o 12 diarios de París (que después se propuso en el Consejo de Estado suprimir y no dejar sino dos en París y uno para cada departamento!) cada uno tiene asignado su rol de reacción y servilismo" (Vicuña Mackenna, 1936, Vol I: 345).

En este escenario, Vicuña Mackenna se interesa también por el análisis del movimiento político-revolucionario francés de 1848, siendo Lamartine uno de los autores que más habría influenciado al joven revolucionario chileno. Aunque en su paso por Francia, como él mismo nos informa, nunca tuvo: "la felicidad de conocer" (Vicuña Mackenna, 1936, Vol I: 320). En todo caso, podemos indicar que su análisis está probablemente descontextualizado, debido a que en su calidad de extranjero no conoce ni comprende en profundidad las complejas relaciones políticas al interior de esta nación. Más allá de estas limitantes, observamos que se esfuerza por elaborar una visión sobre la situación política francesa a través de una analogía o extrapolación histórica que la haga comprensible a sus lectores: 
"Hay en efecto tan estrecha analogía histórica entre Felipe II y Napoleón III que los contrastes y puntos de unión se presentan naturalmente. Herederos ambos de monarcas que habían conquistado la Europa y que abdicando sus coronas murieron, el uno en el monasterio de San Yuste y el otro en Santa Elena, ellos tuvieron delante de sus ojos una palpitante e idéntica lección; se crearon en una misma escuela, adaptaron el mismo fin, el mismo rol, el mismo disfraz. Desposeídos de las conquistas de sus antecesores, toda su grande energía se concentró en la dirección de sus Estados; el Estado eran ellos y por consiguiente su sistema ha sido una misma tiranía” (Vicuña Mackenna, 1936, Vol I: 351).

La "analogía histórica" presentada por el viajero, busca ejemplificar los modos de gobierno despóticos de Napoleón III y Felipe II, donde el autoritarismo y el abuso de poder son los rasgos compartidos por ambos gobernantes. Para Vicuña Mackenna, están signados por el terror que infundían en sus enemigos políticos:

"Felipe II se alzó sobre los Comuneros vencidos, para quienes fue implacable. Napoleón III se ciñó una corona en nombre de la facción vencida que él apellidaba Comunistas. Ambos abrazan un mismo elemento de gobierno: el terror! El uno, según los tiempos, eligió lo que era más terrible y más pronto, la Inquisición; el otro adoptó el elemento predominante del día, las armas" (Vicuña Mackenna, 1936, Vol I: 351).

Aunque la analogía realizada puede ser cuestionada por equiparar desiguales circunstancias históricas, lo que intenta destacar es que detrás de estas monarquías se encuentra el común uso de la violencia política para legitimar sus despotismos y abusos contra los opositores a sus regímenes; violencia que Vicuña Mackenna estima censurable porque no es acorde a su ideario liberal y republicano. De esta forma, considera que la política del emperador se despliega entre la "hipocresía y el fausto" (Vicuña Mackenna, 1936, Vol I: 347). Para él, entonces, "Luis Napoleón es un ser fatídico; su misión es un arcano" (Vicuña Mackenna, 1936, Vol I: 353).

Como hemos visto hasta aquí, Vicuña Mackenna a partir de su experiencia urbana en París examina principalmente la sociedad y política francesas con el objetivo de redimensionar el lugar que ocupa su capital en el marco del proyecto ideológico y cultural de los letrados chilenos e hispanoamericanos. Finalmente, al comparar a la sociedad chilena con la parisina, Vicuña Mackenna postula que la vida cotidiana de su país natal es superior a las comodidades de ese agitado mundo moderno, ya que no logra acostumbrarse ni encuentra un espacio apropiado dentro de éste. Tal situación le genera un sentimiento de desarraigo, añorando esa especie de 
Edén perdido en que se convierte Chile en su discurso idealizador, lugar en que el viajero se siente confortable y feliz:

\begin{abstract}
"Cuando se compara la vida de Chile a la de París parece que no existieran dos cosas más opuestas en la faz de la tierra. Nosotros, desahogados en nuestras anchas casas con nuestros patios, jardines y corrales; libres para dormir de luz a luz [...] Nosotros, felices en nuestro eterno y fácil reposo, comiendo en la mesa de la familia, durmiendo en holgados colchones o bajo la bóveda de azahar de los naranjos en las noches de verano, que contraste no ofrecemos en París, trepados a un tercer o quinto piso, en un aposento que rico o pobre parece una maquinaria de comodidad, pero sin luz, sin espacio, sin rayos de sol que bañen nuestra frente al despertar, sin sombra de árboles ni perfume que nos refresque en el abrasado medio día, sin una vara de espacio en que correr [...] ¡Ay! ya no se vive en su ancha casa, de jardines, patios y corrales! Un portero autómata que responde solo: Non Monsieur! Oui Monsieur! Merci Monsieur! ha reemplazado al personal de la familia; es necesario ir a buscar la comida y el almuerzo al restaurant vecino; es necesario andar con el porta moneda siempre abierto; ya no hay hogar, nuestra vida está en la calle revuelta con la de todos los demás; todo es aquí comodidad mecánica y goces físicos, pero todo seco, mercenario, sin afección, sin vida... Cuántas veces sentía yo mi soledad, al subir la obscura escala de mi aposento en el barrio latino, seguido por el ruido de mis pasos, sin más compañero que mi propia sombra" (Vicuña Mackenna, 1936, Vol I: 305-306).
\end{abstract}

Las comodidades de la moderna ciudad de París no satisfacen a un viajero que pertenece a la élite criolla y oligárquica. Desde la lejanía logra valorar al Chile, de la clase dominante, por sobre los supuestos encantos de la vida y cultura modernas que representa la ciudad luz. De esta forma, cuando Vicuña Mackenna crítica y cuestiona a la sociedad parisina como modelo prestigioso para sus conciudadanos, está proponiendo implícitamente un proyecto político-social particular. Para esta labor, selecciona y se apropia de todos aquellos elementos que resulten útiles para el efectivo desarrollo de las sociedades hispanoamericanas. Su propuesta entonces, no consiste en la imitación pasiva del modelo parisino, sino en una correcta selección y apropiación para beneficio del subcontinente. Desde su punto de vista, la cultura letrada y el cosmopolitismo parisino no son suficientes para Chile, debido a que también es una sociedad dominada por la superficialidad, por lo mecánico, por el dinero, donde la vida familiar y la comunidad nacional no tienen cabida. Frente a París y todo lo que representa, prefiere lo propio. Vicuña Mackenna, entonces, evalúa esta sociedad en clave nacional. Esto puede considerarse también como una forma de re-jerarquizar el mundo europeo, donde el centro, en este caso París, después de su experiencia de viaje pierde su centralidad. 


\section{REFLEXIONES FINALES}

En la breve revisión que hemos realizado sobre los relatos de viajes de Sarmiento y Vicuña Mackenna, notamos varios puntos en común, relacionados principalmente, con el lugar de "ensueño" que ocupaba París en sus perspectivas ideológicas antes del arribo a la metrópoli gala, pues después de su llegada a la metrópoli manifiestan un cierto "desencanto" frente a su sociedad. Observamos además, que tanto Sarmiento como Vicuńa Mackenna a partir de sus experiencias de viaje elaboran una serie de críticas en torno a las costumbres de la sociedad moderna que representaba París. En este sentido, ambos escriben con cierto rechazo sobre el movimiento constante que se da en el interior de la urbe moderna por antonomasia: París. De esta forma, Sarmiento califica a la capital francesa como un "pandemónium, un camaleón", mientras que Vicuña Mackenna, usando también una palabra latina, la considera un "maremágnum". Ambos escenifican que en su deambular por la ciudad experimentan el torbellino que representa la sociedad moderna y que Berman asocia a una atmósfera de "agitación y turbulencia, mareo y ebriedad, expansión de nuevas experiencias, destrucción de los límites morales y ataduras personales, fantasmas en la calle y en el alma” (Berman, 2004: 89).

Por otro lado, intentamos analizar parte del siglo XIX hispanoamericano a través de la experiencia individual y viajera de Domingo Faustino Sarmiento y Benjamín Vicuńa Mackenna. Para esta tarea, tomamos la figura del flâneur, teniendo presentes los planteamientos de Benjamin a la hora de interpretar parte de la mirada y discurso que estos dos criollos hispanoamericanos elaboraron en su paso por París. Desde este punto de vista, creemos que ni Sarmiento ni Vicuña Mackenna, pueden considerarse completamente dos flâneurs al estilo y perspectiva postulados por Benjamin y Baudelaire, sino que corresponden, como hemos intentado establecer, a dos flâneurs hispanoamericanos. Más bien, hay momentos en que sus enunciaciones adoptan una mirada de flâneur en medio de esa gran urbe de la que se sienten un tanto ajenos. Su calidad de foráneos en medio de la multitud, hasta ese entonces inexistente en las ciudades hispanoamericanas, los hace acercarse a ese "estar solo en la multitud" que Baudelaire tanto alababa. Aparece, desde este punto de vista, una subjetividad moderna que se construye desde la distancia al contrastar lo propio con lo ajeno. 
Más allá de estos diagnósticos compartidos hemos querido resaltar, por una parte, el hecho de que la experiencia urbana en París que registran sus textos, nos acerca a un período en que los relatos de viajes eran uno de los géneros discursivos fundamentales para situar el mundo hispanoamericano en el concierto internacional (Sanhueza, 2007). Y por otra, ayudó a la formación de un pensamiento político y crítico latinoamericanista frente al europeismo reinante entre algunos sectores letrados, difundiendo conocimientos a ambos lados del Atlántico con una actitud crítica frente a los modelos civilizatorios de la época, que muchas veces buscaban ser adaptados en nuestro subcontinente de manera irreflexiva. De esta forma, los viajeros se presentan como agentes evaluadores y mediadores de la sociedad y de la cultura del Viejo Continente.

En definitiva, lo que observamos tanto en Sarmiento como en Vicuña Mackenna, es la formación de un proyecto nacional e hispanoamericano que plantea la problemática entre modernización y cultura, es decir, cómo modernizarse sin dejar de lado las identidades nacionales y culturales latinoamericanas; problemática que a finales del siglo XIX Martí en su conocido ensayo "Nuestra América” (1891) conmina a resolver a partir de la siguiente frase poética "Injértese en nuestras repúblicas el mundo, pero el tronco ha de ser el de nuestras repúblicas” (Martí, 2004: 161).

\section{REFERENCIAS}

Anderson, Perry. "Modernidad y revolución”. En Nicolás Casullo (comp.). El debate modernidad-posmodernidad: edición ampliada y actualizada. Buenos Aires: Ediciones Retórica (2004): 107-125.

Barrera, Víctor. "La formación del discurso crítico hispanoamericano (18101870)". Tesis doctoral. Chile: Universidad de Chile, 2005.

Baudelaire, Charles. "Las muchedumbres". En Pequeños poemas en prosa. Barcelona: Editorial BOSCH (1987): 87-88. 
Bello, Andrés. "Comentario a las investigaciones sobre la influencia social de la conquista”. En Ana Figueroa (ed. y comp.). Ensayistas del Movimiento Literario de 1842, Santiago de Chile: Editorial Universidad de Santiago de Chile (2004): 140-156.

Benjamin, Walter. Poesía y capitalismo (Iluminaciones II). Madrid: Ediciones Taurus, 1998.

Berman, Marshall. "Brindis por la Modernidad". En Nicolás Casullo (comp.). El debate modernidad-posmodernidad: edición ampliada y actualizada. Buenos Aires: Ediciones Retórica (2004): 87-105.

"Baudelaire: el modernismo en la calle". En Todo lo sólido se desvanece en el aire. La experiencia de la modernidad. México: Editorial Siglo XXI (2006): 129-173.

Bilbao, Francisco. "El evangelio americano". En José Alberto Bravo (ed.). Francisco Bilbao 1823-1865: el autor y la obra. Santiago de Chile: Editorial Cuarto Propio (2007): 677-757.

Colombi, Beatriz. "El viaje y su relato", Revista de Estudios Latinoamericanos 43 (2006): 11-35.

Donoso, Ricardo. Don Benjamin Vicuña Mackenna. Su vida, sus escritos y su tiempo. 1831-1886. Santiago de Chile: Imprenta Universitaria, 1925.

Errázuriz, Rebeca. "El viaje latinoamericano y el deseo de modernidad: una lectura de los Viajes de Domingo Faustino Sarmiento (1845-1847)". Tesis de Magíster. Chile: Universidad de Chile, 2009.

Escobar, Gustavo. La Ilustración en la filosofía latinoamericana. México: Editorial Trillas, 1980.

Ette, Ottmar. Literatura de viaje. De Humboldt a Baudrillard. México D.F.: UNAM, 2001. 
Revista de Occidente 260 (2003): 102-115.

Fernández, Javier. "Introducción del coordinador". En Domingo Faustino Sarmiento, Viajes por Europa, África y América. Santiago de Chile: Editorial Universitaria y ALLCA XX (1997): 21-25.

Ferrándiz, Francisco. "Benjamín Vicuña Mackenna, viajero extraordinario", Cuadernos Americanos 6 (1953): 188-218.

Fombona, Jacinto. La Europa necesaria. Textos de viaje de la época modernista. Buenos Aires: Beatriz Viterbo Editora, 2005.

González, Francisco Xavier. Aquellos años franceses. 1870-1900. Chile en la huella de París. Santiago de Chile: Ediciones Taurus, 2003.

Harvey, David. París capital de la modernidad. Madrid: Akal, 2008.

Hobsbawm, Eric. La era de la revolución (1789-1848). Barcelona: Editorial Labor, 1991.

Martí, José. "Nuestra América”. En Ensayos y crónicas. Madrid: Ediciones Cátedra, Madrid (2004): 157-168.

Mignolo, Walter. La idea de América Latina. La herida colonialy la opción decolonial. Barcelona: Editorial Gedisa, 2007.

Pierini, Margarita. "Sarmiento en París: viaje al corazón de la Modernidad", Revista Actual 38, Dirección General de Cultura y Extensión de la Universidad de Los Andes, Mérida, Venezuela, (1998): 177-196.

Pratt, Mary Louise. "La reinvención de América/La reinvención de Europa: la autoafirmación criolla”. En Ojos imperiales. Literatura de viajes y transculturación. Buenos Aires: Universidad Nacional de Quilmes (1997): 301-342. 
Rama, Angel. La ciudad letrada. New Jersey: Ediciones del Norte, 1984.

Ramos, Julio. "Decorar la ciudad: crónica y experiencia urbana”. En Desencuentros de la Modernidad en América Latina. Literatura y Política en el siglo XIX. Santiago de Chile: Editorial Cuarto Propio (2003): 149-184.

Romero, José Luis. "Las ciudades patricias". En Latinoamérica. Las ciudades y las ideas. Buenos Aires: Editorial Siglo XXI (2001): 173-246.

Sanhueza, Carlos. Chilenos en Alemania y alemanes en Chile. Viaje y nación en el siglo XIX. Santiago de Chile: DIBAM/LOM, 2006.

"En busca de un lugar en el mundo: viajeros latinoamericanos en la Europa del siglo XIX", Estudos IberoAmericanos 33/2 (2007): 51-75.

Sarmiento, Domingo Faustino. Viajes por Europa, África y América. Santiago de Chile: Editorial Universitaria y ALLCA XX, 1997.

Subercaseux, Bernardo. Historia de las Ideas y de la Cultura en Chile. Tomo I. Sociedad y cultura liberal en el siglo XIX: J. V. Lastarria. Santiago de Chile: Editorial Universitaria, 1997.

"Literatura y prensa de la Independencia, Independencia de la literatura", Revista Chilena de Literatura 77 (2010): 157-180.

Vicuña Mackenna, Benjamín. "Páginas de mi diario durante tres años de viaje 1853-1854-1855”. Obras Completas. Volúmenes I y II. Santiago de Chile: Ediciones de la Universidad de Chile, 1936.

Historia de la jornada del 20 de abril de 1851: una batalla en las calles de Santiago. Santiago de Chile: Instituto de Historia. Pontificia Universidad Católica de Chile, 2003.

Zea, Leopoldo. América en la historia. México: Fondo de Cultura Económica, 1957. 


\section{El pensamiento latinoamericano. México: Editorial Ariel, 1976.}

Zilly, Berthold. " «No soy el huésped, ni el extranjero, sino el miembro de la familia»: Ambivalencia en Viajes por Europa, África i América 1845-47, de Domingo Faustino Sarmiento", Revista de Humanidades: Tecnológico de Monterrey 27-28 (2010): 129-150. 